\title{
Pregnancy morbidity: Situation and determinants in the province of Essaouira - Morocco-
}

\author{
Abdelmounaim Manoussi ${ }^{1 *}$, Abdellatif Baali ${ }^{1}$, Hakima Amor ${ }^{1}$, and Nadia Ouzennou ${ }^{2}$ \\ ${ }^{1}$ University Cadi Ayyad, Semlalia Faculty of Science, Marrakesh, Morocco \\ ${ }^{2}$ The Higher Institute of Nursing and Health Techniques, Marrakesh, Morocco
}

\begin{abstract}
Pregnancy-related morbidity is a public health problem. The main aim of this study is to assess the prevalence of maternal morbidity among childbearing women in Essaouira province (Morocco) and to determine the associated factors. A cross-sectional descriptive and analytical study conducted by questionnaire, surveyed 1184 married women aged between 18 to 49 years. The prevalence of pregnancies morbidity is $55.9 \%(662 / 1184)$. The mains determinants identified is sexually transmitted infections (STIs) with $50.1 \%$ and anaemia with $45.8 \%$. Also, based on the multinomial logistic regression model, the socio-economic level, antenatal care regularity and precocity, pregnancies risks knowledge, distance from health care facilities and place of residence determine the pregnancies morbidity independently. In conclusion, Morocco must address family living conditions, health education, literacy, and other social determinants of health.
\end{abstract}

\section{Introduction}

Maternal health remains a priority of the Sustainable Development Goals (SDGs). It aims to reduce global maternal mortality to less than 70 per 100,000 live births. Since 2000, the rate decreased by $37 \%$, but still, in 2015 , only the world registered 303,000 maternal deaths. Moreover, middle, and low-income countries are particularly concern by maternal mortality (1). However, it represents only a small fraction of the overall poor maternal health burden $(2,3)$. The morbidity of women's significantly increases during pregnancies (4). As studies, shows the occurrence of those complications is more likely frequent in areas with difficult socio-economic conditions. Furthermore, controlling the risk factors remains a challenging subject, in addition to every maternal death, 20 or 30 women's suffer from acute or chronic morbidity pregnancy-related (2) and the main cause remains the lack of primary prevention strategies for most pregnancy complications (5).

Maternal morbidity in developing countries $80 \%$ of maternal deaths were direct causes related. They include bleeding, severe infections, difficult or prolonged deliveries, pregnancy-related hypertension and unsafe abortions (6). The $20 \%$ "indirect causes" includes pregnancy-aggravated diseases, such anaemia, malaria, heart diseases, hepatitis, tuberculosis, sexually transmitted infections (STIs), HIV/AIDS, and diabetes (2). Pregnancy-related complications have a substantial impact on the quality of women life (7). In addition, most of these complications arise during pregnancy and professionals could prevent or treat them

\footnotetext{
*Corresponding author : abdelmounaim.manoussi@ced.uca.ma
} 
(8). However many other pre-pregnancy conditions worsen during gestation, especially if professionals ignore them in the course of care (9). In addition, risks or morbidity complications during pregnancy increase by minority antenatal care (10).

In Morocco, predominant pregnancy morbidity causes remain preventable, notably; hypertensive disorders (pre-eclampsia/eclampsia), infection, and complications of abortion (11). They are responsible for three-quarters of maternal deaths in the postpartum/postabortion period (12). The obstetrical complications, in the province of Essaouira (MarrakechSafi Region), during only the first semester of 2020, caused 04 reported maternal deaths. Those deaths are occurred either at home, in a delivery facility, or during transfer to a hospital (13). Even though the ratio in the province of Essaouira is one primary health care structure for 6554 inhabitants significantly higher than the national level of 12264 inhabitants (14). However, for $49 \%$ of pregnant women, the nearest health care facility is $6 \mathrm{~km}$ travel (15).

The study aims to evaluate the prevalence of maternal morbidity of reproductive-aged women's (15-49 years) in the province of Essaouira and to determine associated sociodemographic and health factors. Effectively, Morocco present a rare number of studies on women's childbearing morbidity and related factors (16).

\subsection{The context of the study}

The province of Essaouira belongs to the Marrakech-Safi Region (MS) and is predominantly rural $(77.6 \%)$. It is the fifth poorest province in Morocco, recording a poverty incidence of $22.1 \%$, more than twice the national average $(8.2 \%)$ and $11.3 \%$ at the regional level. Its vulnerability rate is $22.16 \%$ compared to $14.81 \%$ in the MS region and $12.5 \%$ nationally (17). The activity rate in Essaouira is $45.7 \%$, with $11.7 \%$ of women in the workforce. Illiteracy is $48.9 \%$ affecting women at $60 \%$, the highest in the MS region (17). The economy bases are mainly on handicrafts, fishing, and tourism, with industrial activity accounting for only $0.6 \%$ of regional sales (18). Married women of reproductive age represent $16.4 \%$ of the total population in 2019 . The health infrastructure consists of 68 urban and rural primary health care structures and one hospital with a bed capacity of 310 available beds. The private sector is not well-developed (14). All birthing centers provide emergency obstetric and neonatal care. The number of birth centers does not exceed $1 / 3$ of the expected births.

\section{Subjects and methods}

The current study was based on a sample of 1184 married women aged 18 to 49 years. Survey of pregnancy morbidity concerns the morbidity of the last pregnancy, that each of the 662 women had during the previous year preceding the survey. We chose this time period to obtain reliable information and avoid omissions and memory errors. Initially, we obtained a study authorization from the health authorities. Next, we collected data by questionnaire from randomly selected women who attended primary health care facilities in the province of Essaouira. Through the questionnaire, we collected socio-demographic information; age at the last birth, residency place, educational level, occupation, living standards, health insurance, gestation number, parity, distance health care facilities and cost of access. In addition to, health information's, obstetrical history, pregnancy risks knowledge, last pregnancy planned, antenatal care (ANC), and at previous pregnancy morbidity. The reports collected by the questionnaire were completed and verified through the women's book of health. All participants of the survey gave their consent before data collection. The duration of the survey is from January 2019 to January 2020.

The researchers analyzed the data using the SPSS-PC 10 program. Statistical processing involved the calculation of the frequencies, the means, the standards and the deviations $(\sigma)$.the chi-square test of independence to capture associations between categorical variables 
and understand the performance of each group, binary logistic regression to eliminate confounding factors and capture the weight of variables associated with pregnancy morbidity. Statistical significance was set at the $5 \%$ threshold.

\section{Results}

\subsection{Socio-demographic and health profile}

The range of age at the last pregnancy is 15 to 46 years, with an average of 27.9 years $(\sigma=$ 6.3). $61.1 \%$ from rural areas, $18.2 \%$ from semi-urban areas and. $20.8 \%$ were city residents. The illiteracy rate was $44.3 \%$, with, $36.5 \%$ has a primary level of education, and $19.2 \%$ has secondary and higher education levels. For the spouses, $31.5 \%$ are illiterate, $42 \%$ has reached a primary level, and $26 \%$ are above secondary level. Thus, literate couples represent $46.6 \%$, while illiterate couples represent $22.5 \%$. The annual household income varies from 0 to 432,000 Dirhams (Dh), an average of 38167 Dirhams (Dh) (Moroccan currency, i.e. 4246.85 United States Dollar (USD).The studied women were subdivided into two separate groups according to the value of the GMIW (Guaranteed Minimum Interprofessional Wage). It was 2570 Dh (285.94 USD) in Morocco during the year of 2020 (19). The first group with a relatively low socioeconomic level includes households with a monthly income less than or equal to the SMIG and the second group with a medium to high socio-economic level includes women belonging to households with a monthly income greater than the GMIW. Thus, $44.9 \%$ of women belonged to the first group. Households' incomes calculation were based on the husband's and wife's income, but the proportion of women with socioprofessional activity at the time of the survey represents only $7.7 \%$. In addition, $51.7 \%$ had medical coverage. The number of children per woman varied from 1 to 10 , with an average of children of $2.3(\sigma=1.3) .12 .8 \%$ had an obstetrical problems history, includes at $6.4 \%$ abortion, $2.6 \%$ stillbirth and $3.8 \%$ preterm delivery. Antenatal care coverage (ANC) represents $93.7 \%$ of the cases with a proportion of $56.6 \%$, with regular antenatal care (4 visits). While $37.2 \%$ ANC less than three visits. The proportion of $58.1 \%$ consulted during the 1 st trimester of pregnancy and $31.9 \%$ during the 2 nd trimester. Women who planned their last pregnancy are $86.6 \%$ and $66.8 \%$ knew at least two risks related to pregnancy. The range distance to the nearest health care structure varies from a few meters to $44 \mathrm{~km}$, with an average of $5.9 \mathrm{~km}(\sigma=6.7)$, and $22.7 \%$ of women were more than $6 \mathrm{~km}$ away. To reach to the nearest health care facility, women spend an average of $10.7 \mathrm{DH}$ (Moroccan currency, i.e. 1.16 USD) $(\mathrm{min}=0 \mathrm{DH}$ and $\max =150 \mathrm{DH} / 16.30 \mathrm{USD})(\sigma=13.4)$.

\subsection{Pregnancy morbidity}

Six hundred sixty-two women among 1184 women surveyed had at least one primary or minor morbid sign during their last pregnancy, with the number of symptoms ranging from 1 to 5 . The calculated prevalence of pregnancy morbidity was, therefore, $55.9 \%$. Sexually transmitted infections (STIs) were the leading cause of pregnancy morbidity with a prevalence of $58 \%$, manifested by leucorrhoea, pruritus, dysuria and pelvic pain. Anaemia was present in $53 \%$ of women, followed by gestational diabetes $(9.7 \%)$ and hypertensive disorders of pregnancy (gravidic hypertension, eclampsia, pre-eclampsia) represent (4.8\%).

\subsection{Pregnancy morbidity and women's sociodemographic and health profile}

The results of Table 1 shows that pregnancy morbidity is statistically associated, in order of importance, with the socioeconomic level of the household, early antenatal care, literacy of 
the couple, place of residence, distance from the health care facilities, antenatal care regularity, health insurance, number of children delivered by the woman, pregnancy risks awareness. The multiple logistic regression model (Table 2), demonstrate the sociodemographic and health factors were significantly and independently determinant of pregnancy morbidity. The socio-economic level $(\mathrm{OR}=1.39$; $\mathrm{CI} 1.14-2.23)$, the antenatal care regularity $(\mathrm{OR}=0.76$; $\mathrm{CI} 0.6-0.9)$, earliness of antenatal care $(\mathrm{OR}=1.21$; CI 1.02-1.25), the pregnancy risks knowledge $(\mathrm{OR}=1.33$; $\mathrm{CI} 1.02-1.73)$, the residence $(\mathrm{OR}=0.83$; $\mathrm{CI} 0.7-0.98)$ and the distance from the health care structure $(\mathrm{OR}=0.85$; CI $0.73-0.99)$.

Table 1. Pregnancy morbidity (in \%) and socio-demographic and health profile of women

\begin{tabular}{|c|c|c|c|c|c|}
\hline Variables & Modality & $\mathrm{N}$ & $\mathrm{n} 1$ & $\%$ & Test $\chi^{2}$ \\
\hline \multirow[t]{3}{*}{ Age at last pregnancy } & $15-24$ & 413 & 232 & 19.6 & $0,08 \mathrm{~ns}$ \\
\hline & $25-34$ & 553 & 310 & 26.2 & \\
\hline & $35-49$ & 218 & 120 & 10.1 & \\
\hline \multirow[t]{3}{*}{ Place of residence } & Urban & 246 & 174 & 14.7 & $28.31 * * *$ \\
\hline & Semi-urban & 215 & 117 & 9.9 & \\
\hline & Rural & 723 & 371 & 31.3 & \\
\hline \multirow[t]{3}{*}{ Literacy of the couple } & An Illiterate couple & 266 & 140 & 11.8 & $29,70 * * *$ \\
\hline & One spouse literate & 366 & 169 & 14.3 & \\
\hline & A literate couple & 552 & 353 & 29.8 & \\
\hline \multirow[t]{2}{*}{ Socio-economic level } & Low & 532 & 248 & 20.9 & $33.86^{* * *}$ \\
\hline & Medium to high & 652 & 414 & 35 & \\
\hline \multirow[t]{2}{*}{ Health insurance } & Yes & 612 & 369 & 31.2 & $9.86^{* *}$ \\
\hline & No & 572 & 293 & 24.7 & \\
\hline \multirow[t]{2}{*}{ Children number } & $\leq 2$ & 745 & 436 & 36.8 & $5,55^{*}$ \\
\hline & $>2$ & 439 & 226 & 19.1 & \\
\hline \multirow[t]{4}{*}{ Obstetrical history } & None & 1032 & 574 & 48.5 & $0.85 \mathrm{~ns}$ \\
\hline & Abortion & 76 & 45 & 3.8 & \\
\hline & Stillbirth & 31 & 19 & 1.6 & \\
\hline & Preterm delivery & 45 & 24 & 2 & \\
\hline \multirow[t]{3}{*}{ Regularity of antenatal care } & $>=4$ & 670 & 381 & 32.2 & $10.5^{* *}$ \\
\hline & $1-3$ & 440 & 253 & 21.4 & \\
\hline & 0 & 74 & 28 & 2.4 & \\
\hline \multirow[t]{4}{*}{ Earliness of antenatal care } & 1st trimester & 688 & 360 & 30.4 & $31,57 * * *$ \\
\hline & 2nd trimester & 378 & 239 & 20.2 & \\
\hline & 3rd trimester & 44 & 35 & 3 & \\
\hline & No follow-up & 74 & 28 & 2.4 & \\
\hline \multirow[t]{3}{*}{ Desire for pregnancy } & Yes & 1025 & 575 & 48.6 & $1.95 \mathrm{~ns}$ \\
\hline & No & 120 & 62 & 5.2 & \\
\hline & Don't know & 39 & 25 & 2.1 & \\
\hline \multirow{2}{*}{$\begin{array}{l}\text { Knowledge of pregnancy } \\
\text { risk }\end{array}$} & Yes & 791 & 426 & 36 & $4.08 *$ \\
\hline & No & 393 & 236 & 19.9 & \\
\hline \multirow{3}{*}{$\begin{array}{l}\text { Distance from health care } \\
\text { structures }\end{array}$} & $<$ or $=3 \mathrm{~km}$ & 542 & 324 & 27.4 & $11.61 * *$ \\
\hline & $>3 \mathrm{~km}$ and $<$ or $=6 \mathrm{~km}$ & 373 & 211 & 17.8 & \\
\hline & $>6 \mathrm{~km}$ & 269 & 127 & 10.7 & \\
\hline
\end{tabular}

$\mathrm{N}$ : number of women, n1: number of morbid women, \%: percentage morbidity, ns: not significant, ${ }^{*}$ $\mathrm{p}<0.05$ significant; $* * \mathrm{p}<0.01 ; * * *<.0 .001$ 
Table 2. Odds ratio adjusted for pregnancy morbidity and socio-demographic and health profile of women

\begin{tabular}{lc|c|c}
\hline \multicolumn{1}{c}{ Variables } & $\mathrm{A}$ & $\chi 2$ & OR \\
\hline & & & \\
\hline Literacy of the couple & 0,042 & 0,977 & 1,043 \\
\hline Socio-economic level & 0,549 & $17,827^{* * *}$ & 1,731 \\
\hline Health insurance & $-0,230$ & 3,469 & 0,795 \\
\hline Number of children & $-0,234$ & 3,115 & 0,791 \\
\hline Antenatal care Regularity & $-0,273$ & $5,122^{*}$ & 0,761 \\
\hline Earliness of antenatal care & 0,196 & $4,805^{*}$ & 1,217 \\
\hline Knowledge of pregnancy risks & 0,290 & $4,644^{*}$ & 1,336 \\
\hline Distance to health care structures & $-0,157$ & $3,965^{*}$ & 0,854 \\
\hline
\end{tabular}

A: Constant, OR: Odds ratio (rib ratio) $* \mathrm{p}<0.05$ significant); $* * \mathrm{p}<0.01 ; * * *<.0 .001$

\section{Discussion}

\subsection{Pregnancy morbidity}

The women in our study in the prepartum period had between one and seven signs of morbidity. Thus, the rate of pregnancy morbidity found was $55.9 \%$. In High Atlas, the rate was $8 \%$ in 2009 and $9.7 \%$ in $2010(20,21)$. Nevertheless, the national rate was $44.6 \%$ of women had a complication during pregnancy (11). In India, it was $17.7 \%$ in rural areas.

Concerning symptoms indicating pregnancy morbidity, $58 \%$ of women reported signs indicating an STI (pruritus, leucorrhea, urinary burning, pelvic pain), this rate much higher than the one reported in Western High Atlas (1.7\%) (20) and the one in Marrakech (1\%) (22). But In Kenya, 55\% had STIs, of which 34\% had symptoms (23), compared to $14.9 \%$ and $7.8 \%$ in Pakistan (24). STIs may conceal HIV infection; women with STIs who received either serology or rapid prenatal HIV testing accounted for only $4.1 \%$ and $13.4 \%$, respectively. The cross-tabulation of STIs with other variables showed that women who followed their pregnancy early (as early as the first trimester), regularly (four or more ANCs), lived in a literate couple and knew the risks of pregnancy contracted STIs less $(\mathrm{P}<0.000)$. Other studies have found that women in the age group 20-24 years, urban dwellers, multiparous, illiterate, of low socio-economic class, who had poor genital hygiene are more likely to contract an STI (25).

Anaemia represents the second cause of pregnancy morbidity (53\%), this is higher value than the one found in Essaouira in 2018 (41\%) (26) and the other reported in Temara (Morocco) (16.8\%) (27). Other studies in Essaouira have showed that anemia is associated with low education, primiparity, unemployment, and low socio-economic status $(26,28,29)$. Worldwide, about half of all pregnant women suffer from anaemia (30). It is more common and severe in countries with low social and economic development and represents a common and potentially reversible risk factor associated with pregnancy, intrapartum, and postpartum morbidity (2).

Gestational diabetes represents $9.7 \%$ of our sample; it reaches $23.7 \%$ in Marrakesh (32), between 8.2 and $10 \%$ in Rabat (33), and 10\% in Algeria (34). It affects at least 5\% of women in low-resource countries, and is estimated at $5.1 \%$ in Africa, and $25.1 \%$ in the Western Pacific Region (4). Its treatment is often reserved for specialist physicians, which implies difficulties in accessing higher levels of care and delays in treatment in Morocco (35).

Hypertensive disorders of pregnancy (gestational hypertension, pre-eclampsia, eclampsia, and preexisting hypertension) represent $4.8 \%$ in our study. $87.3 \%$ of the women 
surveyed had at least one blood pressure measurement in prepartum. In Pakistan, 62.1\% reported high blood pressure (36), responsible for one fifth to one-third of all maternal deaths worldwide (37).

\subsection{Pregnancy morbidity and women's socio-demographic and health characteristics}

Using multiple logistic regression model, the socio-demographic and health factors were significant and independent determinants of pregnancy morbidity; were socioeconomic level, regularity, and earliness of antenatal care, knowledge of pregnancy risks, place of residence, and distance from the health care structure.

Our study identified that the Socio-economic level is an essential factor related to pregnancy morbidity. Paradoxically, women with a medium to a high socio-economic status were more likely to have morbidity, which corroborates with a study in Rabat on the one hand (16), and contradicts with others $(38,39)$. The financial accessibility of women at a high socioeconomic level to care, may explain our results, allowing those women to diagnoses more symptoms that are morbid.

Regarding the regularity of antenatal care, women who participate in at least four antenatal visits are more morbid, which means that the more women attend antenatal visits, the more they benefit from screening and diagnosis of potential pregnancy complications. On the other hand, many studies suggest that the quality of the consultation is more important than the number of visits (40). The antenatal care regularity was statistically related to the distance from the nearest health facility $(2=53.3 ; \mathrm{p}<0.001)$, to the number of children $(2=50.3 ; \mathrm{p}<0.001)$ and to the socio-economic level $(2=30 ; \mathrm{p}<0.001)$. Thus, women who regularly monitor their pregnancies travel less than $3 \mathrm{~km}$ to access the nearest health care services, have fewer number of children, and have a medium to high socioeconomic level.

In relation to antenatal care earliness, women who seek it in the first trimester of pregnancy (ANC1) are more morbid. If women delay $\mathrm{ANC1}$, this is a limiting factor for accurate monitoring and detection of pregnancy complications. Whereas the ANC1 precocity allows a delivery prognosis by the fourth antenatal consultation (41). In this study, the precocity of antenatal care (ANC) was statistically influenced $(\mathrm{P}<0.001)$ by the couple's literacy $(2=54.7)$, the number of children $(2=47.4)$, the socio-economic level $(2=34.7)$, and the place of residence $(2=30.9)$. Thus, women living in a literate couple, having less than three children, with a medium to high socio-economic level, and living in an urban area go to antenatal consultation at the first trimester of pregnancy. Same as Uganda, where women with higher education levels and with no money issues were more likely to have early ANC (42). While in Senegal, the unexpectedness of pregnancy, lack of knowledge of risks and refusal of examination by male health care providers, the age at risk $(<18$ years or $>34$ years), multiparity ( $>3$ deliveries) and illiteracy had a statistically significant influence on ANC in the first trimester of pregnancy (41). In addition, knowledge of pregnancy risks in the present study protects against pregnancy morbidity. Literate couples $(2=26 ; p<0.001)$, with a high socio-economic level $(2=7.73 ; p<0.005)$ were more aware of the risks of pregnancy, they consulted more often and at the least risk. However, the lack of risks knowledge was due to the low level of education of women $(44.3 \%$ illiterate and $36.5 \%$ did not go beyond primary school) and the educational insufficiency for antenatal health $(22.1 \%)$. Women suffering from pregnancy complications need to have sufficient information about the morbidity (43). To this end, the Ministry of Health in Morocco has implemented the "Mothers' Class" approach in health facilities, which consists of organizing group educational sessions adapted to pregnant women and women who have given birth. This approach allows the improvement of women's knowledge and attitudes on several topics (44).

Our study also showed that women residing in rural areas are more exposed to pregnancy 
morbidity, which can be explained by their difficult living conditions. They are more likely to have a low socio-economic level $(2=142.6 ; \mathrm{p}<0.001)$. In addition, the distance of less than $3 \mathrm{~km}$ to reach a health care structure is a determining factor, as women who have easy access to ANC are more morbid, and this ease of access encourages them to consult when they are facing a pregnancy-related problem.

Finally, the prevalence estimations by self-reported morbidity are generally more specific than sensitive estimates (16). However, diagnosis by interview may be the only way to get an insight into the prevalence of certain types of maternal morbidity and into the information needed to improve obstetric care and, finally women global health status (45). In industrialized countries, women themselves report more complaints (46). This study combined two methods of data collection, primarily questionnaire interviews with women, supplemented by analysis of their health book. Nevertheless, it still this study may be not able to describe the true extent of pregnancy morbidity. For some reasons like a lake of exhaustive documentation in women's health book of the minor signs of pregnancy (vomiting, oedema, dizziness, tiredness). Since women generally do not declare them, as they consider them, physiological discomfort of pregnancy. On the other hand, the STIs reported by women are symptomatic ones, but the authors indicate that STIs and genital infections are often asymptomatic (23).

Therefore, this study opens perspectives to research asymptomatic STIs pregnancyrelated, the psychological issues of pregnant women (anxiety, depression, mental disorders, etc.) and social issues (domestic violence), the association nutrition on and pregnancy and finally the antenatal morbidity.

\section{Conclusion}

The prevalence of pregnancy morbidity identified by this study was $55.9 \%$. STIs and anaemia are the leading causes. This may affect the outcome of the pregnancy. Antenatal screening and early treatment should be a priority. Multivariate analysis has shown that the socioeconomic level, the regularity and precocity of antenatal visits, the knowledge of pregnancy risks, the place of residence and the distance from the health care structure determine independently the pregnancy morbidity. It is necessary to act on family living conditions, health education and illiteracy, and other social determinants of health.

\section{Bibliographie}

1. Alkema L, Chou D, Hogan D, Zhang S, Moller A-B, Gemmill A, et al. Global, regional, and national levels and trends in maternal mortality between 1990 and 2015, with scenario-based projections to 2030: a systematic analysis by the UN Maternal Mortality Estimation Inter-Agency Group. The Lancet. 30 Janv 2016;387(10017):462-74.

2. Chou D, Tunçalp Ö, Firoz T, Barreix M, Filippi V, von Dadelszen P, et al. Constructing maternal morbidity - towards a standard tool to measure and monitor maternal health beyond mortality. BMC Pregnancy and Childbirth. 2 mars 2016;16(1):45.

3. Firoz T, Chou D, von Dadelszen P, Agrawal P, Vanderkruik R, Tuncalp O, et al. Measuring maternal health: focus on maternal morbidity. Bull World Health Organ. 6 août 2013;91:794-6.

4. Gon G, Leite A, Calvert C, Woodd S, Graham WJ, Filippi V. The frequency of maternal morbidity: A systematic review of systematic reviews. Int J Gynecol Obstet. Mai 2018; 141:20-38. 
5. Lu MC, Noursi S. Summary and Conclusion: Framing a New Research Agenda on Maternal Morbidities and Mortality in the United States. J Womens Health. 1 févr 2021; 30(2):280-4.

6. Prual, Bouvier-Colle, L. de Bernis, G. Bréart and the MOMA group. Severe maternal morbidity from direct obstetric causes in West Africa: incidence and case fatality. Bulletin of the World Health Organization. 2000; 593-602.

7. United Nations. Goal 3: Sustainable Development Knowledge Platform [Internet]. https://sustainabledevelopment.un.org/. 2019 [cited 30 Apr 2020]. Available at: https://sustainabledevelopment.un.org/sdg3

8. Ashford L. HIDDEN SUFFERING: Disabilities from Pregnancy and Childbirth in Less Developed Countries. 2002;6.

9. Guida JP, Costa ML, Parpinelli MA, Pacagnella RC, Ferreira EC, Mayrink J, et al. Maternal morbidity during labor and the puerperium in rural homes and the need for medical attention: A prospective observational study in Gadchiroli, India. Int J Gynecol Obstet. mai 2018;141:55-60

10. OMS. Mortalité maternelle [Internet]. 2019 [cité 21 sept 2020]. Disponible sur: https://www.who.int/fr/news-room/fact-sheets/detail/maternal-mortality

11. ENPSF. Enquête Nationale sur La Population et la Santé Familiale (ENPSF -2018) [Internet]. Maroc; 2018 p. 312. Disponible sur: https://www.unicef.org/morocco/media/1626/file/Enqu\%C3\%AAte $\% 20$ Nationale $\% 20$ sur\%20La\%20Population\%20et\%201a\%20Sant $\%$ C3\%A9\%20Familiale $\% 20$ (ENPSF\% 20-2018).pdf

12. Ministère de la santé. Enquête confidentielle sur les décès maternels de 2015 dans les six régions prioritaires au Maroc [Internet]. 2015. Disponible sur: https://www.sante.gov.ma/Publications/Documents/rapport\%20SSDM\%20final\%20Ed it $\%$ C3\%A9\%20d\%C3\%A9c\%202015\%20.pdf

13. SRES Essaouira. Bilan annuel de la province d'Essaouira. Essaouira: Bureau des statistiques; 2020.

14. Ministère de la santé. FICHE SUR L'OFFRE DE SOINS DE SANTE EXISTANT PROVINCE SANITAIRE: ESSAOUIRA [Internet]. 2019 [cité 30 juin 2020]. Disponible sur: http://cartesanitaire.sante.gov.ma/fd?p_iddel $=211$

15. Direction régionale de la santé M-S. Schéma régional de l'offre de soins (SROS) de la région Marrakech-Safi. 2019.

16. Assarag B, Dubourg D, Maaroufi A, Dujardin B, De Brouwere V. Maternal postpartum morbidity in Marrakech: what women feel what doctors diagnose? BMC Pregnancy Childbirth. déc 2013;13(1):225.

17. HCP. Maroc en carte, la province d'Essaouira [Internet]. Haut commissariat au Plan. 2014 [cité 10 déc 2020]. Disponible sur: http://rgphencartes.hcp.ma/

18. CCIS. Monographie de la province d'Essaouira [Internet]. Chambre de commerce, d'industrie et de services, de marrakech-safi; 2016 p. 13. Disponible sur: https://www.ccisrms.ma/wp-content/uploads/pdf/Essaouira.pdf

19. Machrafi K. Gestion de la paie Maroc: Valeur du SMIG au 01 Janvier 2019 | BLOG OJRAWEB [Internet]. 2019 [cité 8 sept 2020]. Disponible sur: https://blog.ojraweb.com/gestion-de-la-paie-maroc-valeur-du-smig-au-01-janvier2019/

20. Zouini M, Baali A, Cherkaoui M, Hilali MK, Vimard P. Morbidité maternelle et recours aux soins dans le Haut Atlas occidental au Maroc : l'exemple des vallées d'Azgour et 
d'Anougal (cercle d'Amizmiz). In 2009 [cité 12 juill 2020]. Disponible sur: https://hal.ird.fr/ird-00591846

21. Zouini M, Baali A, Cherkaoui M, Amor H, Hilali MK, Vimard P. Etude de la morbidité maternelle des populations rurales du Haut Atlas occidental marocain. 30 nov 2010;135.

22. El Hamdani FZ, Zouini M, Baali A, Aboussad A, Baudot P, Vimard P, et al. Morbidité et recours aux soins de santé maternelle des femmes de la ville de Marrakech. Relation avec l'exode rural et les facteurs socio-économiques et biodémographiques. Bull Mém Soc Anthropol. déc 2012;24(3-4):179-89.

23. Warr AJ, Pintye J, Kinuthia J, Drake AL, Unger JA, McClelland RS, et al. Sexually transmitted infections during pregnancy and subsequent risk of stillbirth and infant mortality in Kenya: a prospective study. Sex Transm Infect. févr 2019;95(1):60-6.

24. Zafar S, Jean-Baptiste R, Rahman A, Neilson JP, Broek NR. Non-life threatening maternal morbidity: cross sectional surveys from Malawi and Pakistan. PLoS One [Internet]. 2015;10. Disponible sur: https://doi.org/10.1371/journal.pone.0138026

25. Aral SO. Sexually transmitted diseases: magnitude, determinants and consequences. Int J STD AIDS. avr 2001;12(4):211-5.

26. Ouzennou N, Tikert K, Belkedim G, Jarhmouti FE, Baali A. Prevalence and social determinants of anemia in pregnant women in Essaouira Province, Morocco. Sante Publique. oct 2018;30(5):737-45.

27. Hasswane N, Bouziane A, Mrabet M, Laamiri FZ, Aguenaou H, Barkat A. Prevalence and Factors Associated with Anemia Pregnancy in a Group of Moroccan Pregnant Women. Journal of Biosciences and Medicines. 2015;03(10):88.

28. Moccia P, Unicef. La situation des enfants dans le monde 2009: [la santé maternelle et néonatale. New York: Le Fonds des Nations Unies pour l'enfance (UNICEF); 2008.

29. Ouzennou N, Amor H, Baali A. Socio-economic, cultural and demographic profile of a group of Moroccan anaemic pregnant women. Afr Health Sci. sept 2019;19(3):2654-9.

30. Moccia P, Unicef. La situation des enfants dans le monde 2009: [la santé maternelle et néonatale. New York: Le Fonds des Nations Unies pour l'enfance (UNICEF); 2008.

31. Smith C, Teng F, Branch E, Chu S, Joseph KS. Maternal and Perinatal Morbidity and Mortality Associated With Anaemia in Pregnancy: Obstetrics \& Gynecology. déc 2019;134(6):1234-44.

32. Utz B, Assarag B, Smekens T, Ennassiri H, Lekhal T, Ansari NE, et al. Detection and initial management of gestational diabetes through primary health care services in Morocco: An effectiveness-implementation trial. PLOS ONE. 28 déc 2018;13(12):e0209322.

33. Bouhsain S, El Kochri S, Babahabib MA, Hafidi MH, Bouaiti E, Moussaoui MD. Comparaison de deux politiques de dépistage du diabète gestationnel : expérience de l'hôpital militaire d'instruction Mohammed V de Rabat (Maroc). Gynécologie Obstétrique \& Fertilité. 1 mai 2014;42(5):317-21.

34. Hannat S, Chermat R, Fellahi S, Malek R. P217 Diabète gestationnel: résultats d'un dépistage systématique. Diabetes \& Metabolism. 1 mars 2009;35:A78.

35. Utz B, Assarag B, Essolbi A, Barkat A, El Ansari N, Fakhir B, et al. Improving detection and initial management of gestational diabetes through the primary level of care in Morocco: protocol for a cluster randomized controlled trial. Reproductive Health. 19 juin 2017;14(1):75. 
36. Sheikh S, Qureshi RN, Raza F, Memon J, Ahmed I, Vidler M, et al. Self-reported maternal morbidity: Results from the community level interventions for pre-eclampsia (CLIP) baseline survey in Sindh, Pakistan. Pregnancy Hypertens. juill 2019;17:113-20.

37. Davies AM. Epidémiologie des troubles hypertensifs de la grossesse. Bull World Health Organ. 1979;57(4):555-70.

38. Assarag B, Dujardin B, Essolbi A, Cherkaoui I, De Brouwere V. Consequences of severe obstetric complications on women's health in Morocco: please, listen to me! Trop Med Int Health. nov 2015;20(11):1406-14.

39. Ugwu GO, Iyoke CA, Ezugwu EC, Ajah LO, Onah HE, Ozumba BC. A Comparison of the Characteristics of Maternal Near-Misses and Maternal Deaths in Enugu, Southeast Nigeria: A 3-Year Prospective Study. Int J Womens Health. 2020;12:207-11.

40. Kinzie B, Gomez P. Soins maternels et néonatals de base : un guide destiné au prestataire qualifié. JHPIEGO: MNH Program : Baltimore, MD.; 2004.

41. N'Diaye P, Dia AT, Diediou A, Dieye EHL, Dione DA. Déterminants socioculturels du retard de la 1re consultation prénatale dans un district sanitaire au Sénégal. Santé Publique. 2005;17(4):531.

42. Atuhaire R, Atuhaire LK, Wamala R, Nansubuga E. Interrelationships between early antenatal care, health facility delivery and early postnatal care among women in Uganda: a structural equation analysis. Glob Health Action. 31 déc 2020;13(1):1830463.

43. Meaney S, Lutomski JE, O' Connor L, O' Donoghue K, Greene RA. Women's experience of maternal morbidity: a qualitative analysis. BMC Pregnancy Childbirth. 25 juill 2016;16:184.

44. Ministère de la santé. Classe des mères: Guide méthodologique à l'usage des professionnels de santé. Rabat, Maroc; 2015.

45. Stewart MK, Stanton CK, Festin M, Jacobson N. Issues in measuring maternal morbidity: lessons from the philippines safe motherhood survey project. Stud Fam Plann [Internet]. 1996;27. Disponible sur: https://doi.org/10.2307/2138075

46. Hogan MC, Foreman KJ, Naghavi M, Ahn SY, Wang M, Makela SM, et al. Maternal mortality for 181 countries, 1980-2008: a systematic analysis of progress towards Millennium Development Goal 5. The Lancet. 8 mai 2010;375(9726):1609-23. 